\title{
Accuracy of Conventional MRI in ALS
}

\author{
Aparna Gupta, Thanh Binh Nguyen, Santanu Chakraborty, Pierre R. Bourque
}

\begin{abstract}
Background: There is currently no definite neuroimaging test to detect amyotrophic lateral sclerosis (ALS), which leads to significant delay in diagnosis, particularly if one takes into account the rapidity of disease evolution. Hyperintensity of the corticospinal tracts (CST) on T2 or fluid-attenuated inversion recovery (FLAIR) weighted magnetic resonance imaging (MRI) has been well described, but data on sensitivity and specificity in larger series is lacking to help guide its application to clinical care. Methods: We analyzed clinical and MRI data from 64 patients with a definite retrospective diagnosis of ALS. In this case-control study, two experienced blinded neuroradiologists systematically assessed defined rostrocaudal segments of the intracranial course of the CST. Results: The overall sensitivity and specificity of conventional MRI for the diagnosis of ALS were $48 \%$ and $76 \%$ respectively. Highest specificities for CST hyperintensity were noted for the subcortical white matter (92\%), centrum semiovale (88\%) and medullary pyramids $(92 \%)$. The lowest specificities were found for the cerebral peduncle $(36 \%)$ and internal capsule $(32 \%)$. We did not find a correlation with the rate of clinical progression, age of onset or the presence of upper motor neuron signs on examination. Conclusion: Conventional MRI was not found to be a reliable diagnostic tool for ALS and it did not help predict clinical characteristics such as speed of evolution or prominence of upper motor neuron signs. Its main role in the setting of ALS should remain to help exclude alternative diagnostic considerations. A multimodal approach relying on newer functional and structural MRI techniques still needs to be developed and validated.
\end{abstract}

RÉSUMÉ: Précision de l'IRM conventionnelle dans la SLA. Contexte : Il n'existe pas actuellement de test de neuroimagerie pour détecter la SLA, ce qui occasionne des délais importants dans le diagnostic de la maladie, particulièrement si on tient compte de la rapidité d'évolution de celle-ci. Une hyperintensité des faisceaux pyramidaux (FP) sur les séquences pondérées en T2 ou FLAIR de l'imagerie par résonance magnétique (IRM) a été bien décrite, mais il n'existe pas de données sur sa sensibilité et sa spécificité chez de plus grandes séries de patients pour guider son application en clinique. Méthode : Nous avons analysé les données cliniques et d'IRM de 64 patients chez qui un diagnostic rétrospectif définitif de SLA avait été posé. Dans cette étude cas-témoin, deux neuroradiologistes d'expérience ont évalué systématiquement en aveugle des segments rostrocaudaux bien définis de la portion intracrânienne des FP. Résultats : La sensibilité et la spécificité globales de l'IRM conventionnelle pour le diagnostic de la SLA étaient respectivement de $48 \%$ et $76 \%$. Les spécificités les plus élevées pour l'hyperintensité des FP ont été observées pour la substance blanche sous-corticale $(92 \%)$, le centre ovale de Vieussens $(88 \%)$ et les pyramides médullaires $(92 \%)$. Les spécificités les plus faibles ont été observées pour le pédoncule cérébral $(36 \%)$ et la capsule interne (32\%). Nous n'avons pas observé de corrélation avec la rapidité de progression clinique, l'âge de début ou la présence de signes du neurone moteur supérieur à l'examen. Conclusion : Selon nos observations, l'IRM conventionnel n'était pas un outil diagnostic fiable dans la SLA et n'aidait pas à prédire les caractéristiques cliniques telles la rapidité d'évolution ou l'importance des signes du neurone moteur supérieur. Son principal rôle dans le contexte de la SLA devrait se limiter à l'exclusion d'autres pathologies. Une approche multimodale fondée sur des techniques plus récentes d'IRM fonctionnelle et structurelle devra être développée et validée.

Can J Neurol Sci. 2014; 41: 53-57

Conventional magnetic resonance imaging (MRI) of brain and spinal cord is an essential diagnostic tool to exclude amyotrophic lateral sclerosis (ALS) "mimics", when a plausible alternative neuroanatomical localization is suspected ${ }^{1}$. The finding of hyperintensities along the course of corticospinal tracts (CST) on T2, Proton density (PD) or fluid-attenuated inversion recovery (FLAIR) was documented over 25 years ago in case reports and subsequent small series. The sensitivity of such changes has commonly been estimated to be less than $40 \%$ and the specificity is also poor, typically less than $70 \%{ }^{2-12}$. Poor specificity values reflect the occurrence of similar hyperintensities in normal controls ${ }^{13,14}$, as well as widely varying conditions, such as leukodystrophies ${ }^{15,16}$, X-linked CharcotMarie-Tooth disease ${ }^{17}$, end stage cirrhosis and liver transplantation $^{18}$. A 2010 guideline from the European Federation of Neurological Societies states that such hyperintensities may help to support a suspicion of ALS but that "the specific search for these abnormalities for the purpose of making a firm diagnosis of ALS is not recommended"1.

Our aim was to re-evaluate sensitivity and specificity of CST hyperintensities on conventional MRI in a larger series, while attempting to correlate findings with specific features of the clinical course (upper motor neuron signs, speed of evolution from onset to death, timing of MRI in relation to disease onset).

From the Departments of Medicine (Neurology) (AG, PRB), Diagnostic Imaging (TBN, SC), University of Ottawa, Ottawa, Ontario, Canada.

Received April 22, 2013. Final Revisions Submitted August 26, 2013. Correspondence to: Pierre Bourque, The Ottawa Hospital (Civic Campus), Room C2178, 1053 Carling Ave , Ottawa, Ontario, K1Y-4E9, Canada.

Email: pbourque@toh.on.ca. 
We also assessed systematically the frequency of involvement of specific rostrocaudal segments of the intracranial CST.

\section{Methods}

This case control study was based on patients assessed at the Ottawa ALS Clinic in 2004-2010. The Clinic maintains records documenting laboratory investigations, as well as symptoms and clinical neurological examination findings at regular visits, typically every three to six months. We identified patients from the ALS Clinic database who had undergone the appropriate clinical, electrophysiological, laboratory and imaging assessments relevant for the diagnosis of ALS and the exclusion of alternative etiologic considerations. We entered in this study patients who met all of the following criteria: eventual diagnosis of "definite" ALS by revised El Escorial criteria or death at a clinical stage meeting the "probable" or "probable-laboratory supported" criteria, availability of brain MRI with suitable conventional sequences [axial T1, T2, fluid-attenuated inversion recovery (FLAIR)], and availability of documentation of clinical examination findings within three months of MRI imaging study.

For controls, we randomly selected 25 brain MRI studies from older adult patients who were referred for other neurological disorders, namely epilepsy, headache, vertigo, numbness or transient ischemic attack (TIA). We excluded cases of obvious focal pathology such as hydrocephalus, hemorrhagic or ischemic stroke, or any space-occupying lesions.

This project received ethics approval from the Ottawa Hospital Research Institute as a chart review case-control study. All patient identification information was removed for data analysis: clinical and imaging data were entered in a passwordprotected numerical case list.

\section{Clinical Data}

At the point in time closest to the time when the MRI was performed, we extracted from the patient chart the following clinical information: age, revised El Escorial Criteria ALS diagnostic category (Possible, Probable, Definite); presence of symptoms or signs of upper motor neuron involvement in bulbar, cervicobrachial and lumbosacral territories; presence of lower motor neuron signs in bulbar, cervicobrachial and lumbosacral territories. The determination of upper motor neuron involvement was based on the documentation of pseudobulbar emotional incontinence, pathologically increased jaw jerk or gag reflex, spasticity, pathological limb hyperreflexia and presence of a Babinski or Chaddock sign. The determination of lower motor neuron involvement was based on the documentation of frequent fasciculations or definite electromyogram (EMG) evidence of denervation with chronic reinnervation (fibrillations, positive sharp waves, fasciculation potentials, reduced recruitment, markedly polyphasic and long duration motor unit potentials). Based on the time from symptom onset to death, we categorized the rate of evolution of ALS as rapid (less than 18 months), average (18-30 months) or slow (greater than 30 months).

\section{MRI}

Magnetic resonance imaging scans were performed on a $1.5 \mathrm{~T}$ device, with a slice thickness of $5 \mathrm{~mm}$, applying standard sequence settings for T2(TR 4140ms, TE 94ms, FA 180) and FLAIR (TR 9,000ms, TE 99ms, FA 180, TI 2500ms). Two experienced neuroradiologists independently reviewed the scans in a blinded fashion. For controls, we used 25 MRI studies on aged matched patients without ALS, stroke, tumor or trauma.

Each radiologist rated scans for presence of atrophy at the level of the precentral gyrus cortex (PC) and abnormal hyperintensity of the CST in the following locations: precentral gyrus, subcortical white matter, centrum semiovale, corona radiata, posterior limb of the internal capsule, cerebral peduncle, basis pontis and medullary pyramid. Radiologists were also asked to give an overall assessment of whether the study was likely "positive" or "negative" for ALS based on the overall assessment of FLAIR and T2 sequences for corticospinal tract hyperintensities and precentral gyrus atrophy. This overall interpretation was coined "combined MRI assessment". When there was divergence about attribution of abnormality at a specific location or modality, a consensus opinion was subsequently obtained for data analysis, while the neuroradiologists were still blinded for the diagnosis.

Overall sensitivity and specificity of MRI in the diagnosis of ALS was calculated for each reader and for the consensus interpretation. Sensitivity and specificity was also determined in relation to age ( $<60$ vs $>60)$ and disease category (possible vs probable/definite). Diagnostic accuracy of each specific radiological finding on MRI (such as hyperintensity in the internal capsule) was examined. Inter-observer variability was assessed using Cohen's kappa statistics.

With a sample size of 64 patients, we calculated that the study had a power of $80 \%$ to detect an absolute difference of $25 \%$ in the rate of MRI abnormality between ALS subjects and controls.

\section{RESULTS}

Sixty-four patients met inclusion criteria, out of 183 patients seen at the Ottawa ALS Clinic in 2004-2010. The main reason for exclusion in the remaining 119 subjects was the lack of availability of suitable brain MRI raw data, as MRI of the spine alone was the most frequent neuroimaging strategy chosen by treating physicians.

The group of 64 ALS patients was comprised of 35 women and 29 men, with a mean age of 64 years. Forty per cent of subjects in the study group were younger than 60 years, while $60 \%$ were 60 years or older. At the time of MRI, revised El Escorial diagnostic category assignments were 5 definite, 16 probable and 43 possible. The 25 control subjects were comprised of 14 women and 11 men, with a mean age of 59 years.

\section{Diagnostic accuracy of MRI in the diagnosis of ALS}

The sensitivity of the combined assessment of all MRI sequences for the diagnosis of ALS was $48 \%$. It did not differ between ALS patients who were older ( $>60$ years, $48 \%$ ) or younger $(<60$ years, $49 \%)$. It was higher for the El Escorial diagnostic categories probable/definite $(57 \%)$ than possible (44\%), though this difference did not reach statistical significance ( $\mathrm{p}=0.44$ on a Chi square test for proportions). The overall specificity of MRI was $76 \%$ and did not differ between the probable/definite (76\%) and the possible groups (76\%). 
Table 1: Global rating of T2, FLAIR and presence of precentral gyrus abnormality

\begin{tabular}{l|l|l|l|l}
\hline & $\begin{array}{l}\text { CST Hyperintensity } \\
\text { T2 Sequences }\end{array}$ & $\begin{array}{l}\text { CST Hyperintensity } \\
\text { FLAIR Sequences }\end{array}$ & $\begin{array}{l}\text { Grey matter (cortical) } \\
\text { abnormality }\end{array}$ & $\begin{array}{l}\text { Combined MRI } \\
\text { assessment }\end{array}$ \\
\hline ALS (N=64) & 37 & 35 & 12 & 31 \\
\hline Controls (N=25) & 15 & 12 & 2 & 6 \\
\hline Sensitivity* & $58 \%(0.45-0.70)$ & $55 \%(0.42-0.67)$ & $19 \%(0.10-0.31)$ & $48 \%(0.37-0.60)$ \\
\hline Specificity* & $40 \%(0.22-0.61)$ & $52 \%(0.32-0.72)$ & $92 \%(0.72-0.99)$ & $76 \%(0.57-0.89)$ \\
\hline
\end{tabular}

$\mathrm{CST}=$ corticospinal tracts; ALS=amyotrophic lateral sclerosis; FLAIR=fluid-attenuated inversion recovery;

MRI=magnetic resonance imaging; (* 95\% confidence intervals stated in brackets)

Overall, T2 and FLAIR sequences had a similar accuracy (Table 1). The assessment of precentral grey matter atrophy provided high specificity $(92 \%)$ at the expense of very low sensitivity (19\%) (Table 1).

With regard to the assessment of T2 hyperintensity in specific segments of the intracranial CST (Figure 1), the highest specificity values were obtained for the subcortical whitematter $(92 \%)$ and medullary pyramid $(92 \%)$ whereas both the internal capsule and the cerebral peduncle had very low specificity (Table 2).

For the key clinical feature of upper versus lower motor neuron involvement, there was no statistically significant difference in the probability of finding MRI abnormalities along the CST with either T2 or FLAIR imaging. The overall rates of MRI abnormality for CST hyperintense signal in patients with UMN versus LMN involvement were $52 \%$ / $45 \%$ for the bulbar territory, 58\% / 55\% for the upper limb and 51\% / 49\% for the lower limb.

The rate of disease progression could be reliably determined from the chart review in 55/64 subjects. It was categorized as rapid (<18 months) in 18\%, average (18-30 months) in 36\% and slow ( $>30$ months) in $45 \%$. The mean times from symptom onset to MRI testing in these groups were respectively 5.8 months, 10 months and 18 months. The overall rate of MRI positivity did
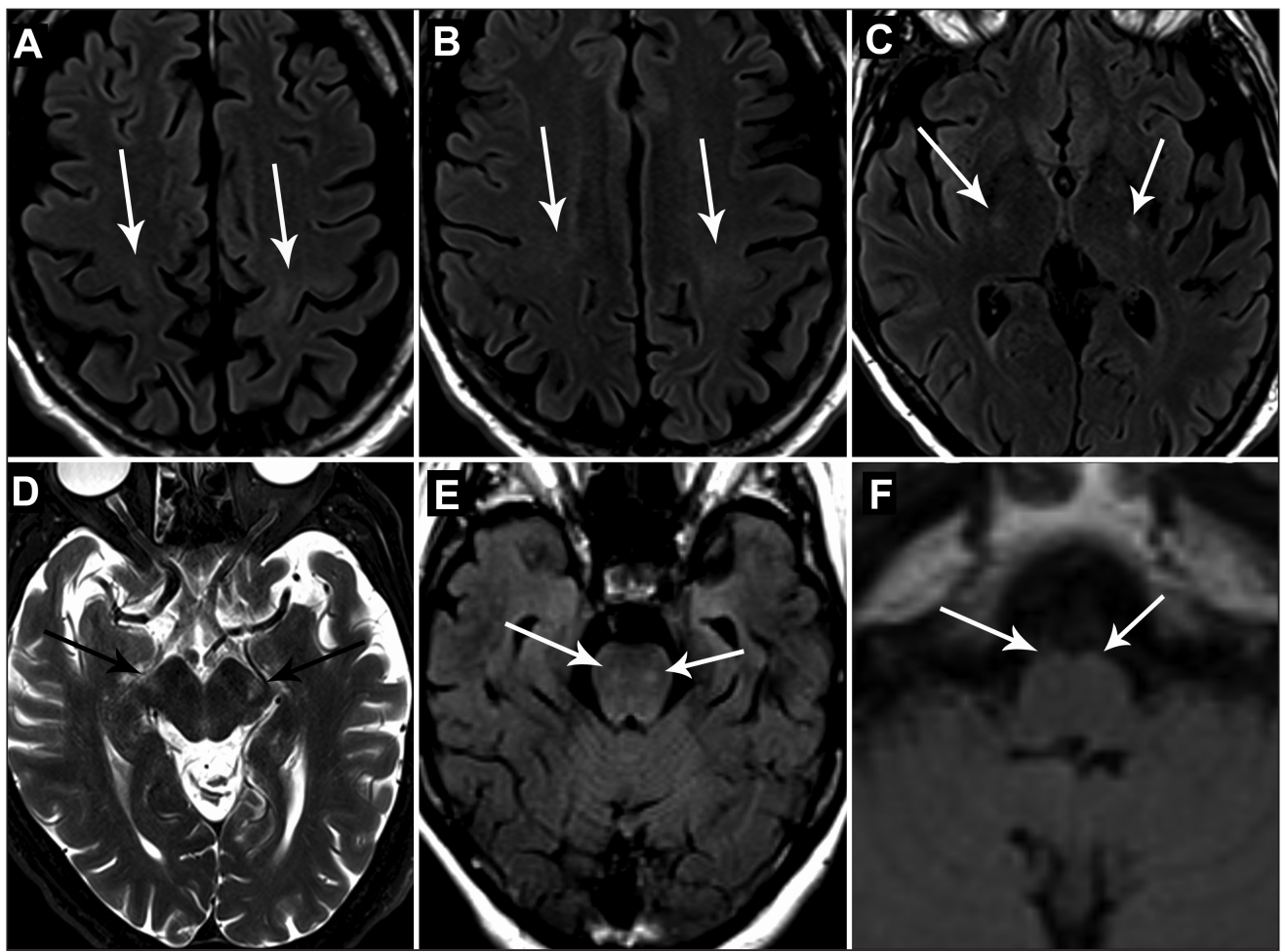

Figure: Axial MRI with FLAIR $(A, B, C, E, F)$ and $T 2(D)$ sequences. Arrows point to hyperintensity of the corticospinal tract in the following locations: subcortical frontal $(A)$, centrum semiovale $(B)$, posterior limb of internal capsule $(C)$, cerebral peduncle $(D)$, basis pontis $(E)$ and medullary pyramid $(F)$. 
Table 2: MRI FLAIR sequence abnormalities at various levels of Corticospinal Tract

\begin{tabular}{|c|c|c|c|c|c|c|c|c|}
\hline & $\begin{array}{l}\text { Precentral } \\
\text { Gyrus Atrophy }\end{array}$ & $\begin{array}{l}\text { Subcortical } \\
\text { w. matter }\end{array}$ & $\begin{array}{l}\text { Centrum } \\
\text { semiovale }\end{array}$ & $\begin{array}{l}\text { Corona } \\
\text { Radiata } \\
\end{array}$ & $\begin{array}{l}\text { Internal } \\
\text { Capsule }\end{array}$ & $\begin{array}{l}\text { Cerebral } \\
\text { Peduncle }\end{array}$ & $\begin{array}{l}\text { Basis } \\
\text { Pontis }\end{array}$ & $\begin{array}{l}\text { Medullary } \\
\text { Pyramid }\end{array}$ \\
\hline ALS (N=64) & 20 & 25 & 36 & 31 & 40 & 34 & 27 & 13 \\
\hline $\begin{array}{l}\text { Controls } \\
(\mathrm{N}=25)\end{array}$ & 4 & 2 & 3 & 8 & 17 & 14 & 5 & 2 \\
\hline Sensitivity* & $\begin{array}{l}31 \% \\
(0.21-0.44)\end{array}$ & $\begin{array}{l}39 \% \\
(0.27-0.52)\end{array}$ & $\begin{array}{l}56 \% \\
(0.43-0.68) \\
\end{array}$ & $\begin{array}{l}48 \% \\
(0.36-0.61) \\
\end{array}$ & $\begin{array}{l}63 \% \\
(0.49-0.74) \\
\end{array}$ & $\begin{array}{l}53 \% \\
(0.40-0.66) \\
\end{array}$ & $\begin{array}{l}42 \% \\
(0.30-0.55)\end{array}$ & $\begin{array}{l}20 \% \\
(0.11-0.32) \\
\end{array}$ \\
\hline Specificity* & $\begin{array}{l}84 \% \\
(0.63-0.95)\end{array}$ & $\begin{array}{l}92 \% \\
(0.72-0.98)\end{array}$ & $\begin{array}{l}88 \% \\
(0.68-0.97)\end{array}$ & $\begin{array}{l}68 \% \\
(0.46-0.84)\end{array}$ & $\begin{array}{l}32 \% \\
(0.16-0.53)\end{array}$ & $\begin{array}{l}36 \% \\
(0.25-0.65)\end{array}$ & $\begin{array}{l}80 \% \\
(0.59-0.92)\end{array}$ & $\begin{array}{l}92 \% \\
(0.72-0.98)\end{array}$ \\
\hline
\end{tabular}

ALS=amyotrophic lateral sclerosis; (*95\% confidence intervals stated in brackets)

not correlate with rate of disease progression: $52 \%$ (rapid), $40 \%$ (average), and $60 \%$ (slow). There was also no direct correlation between MRI positivity and the time interval from symptom onset to performance of the MRI study.

\section{Inter-observer agreement}

The inter-observer agreement for MR interpretation for all study patients was moderate (Cohen's kappa $=0.457,95 \%$ CI 0.255 to 0.659$)$. For patients with ALS, the inter-observer agreement was substantially positive (Cohen's kappa $=0.626$, $95 \%$ CI 0.417 to 0.834 ). For control patients, the inter-observer agreement was negative (Cohen's kappa $=-0.238,95 \%$ CI -0.397 to -0.0780$)$, indicating a potential systematic disagreement between the two interpreting neuroradiologists.

\section{DISCUSSION}

This case- control study is one of the largest published series on the diagnostic accuracy of conventional MRI sequences in patients with ALS. We found an overall low sensitivity (48\%) for CST hyperintense signal on both T2 and FLAIR imaging in 64 ALS patients. Most publications on this topic have not systematically reported specificity and sensitivity statistics, and some relied on relatively small case series. Our results are nonetheless in keeping with the low diagnostic yield reported in most available literature ${ }^{2-12}$.

Our study draws attention to the higher specificity values obtained for T2 hyperintensity at the level of the subcortical white matter of the precentral gyrus, as well as the medullary pyramid, while the internal capsule and cerebral peduncle show remarkably low specificity. Focal signal-intensity variations in the posterior internal capsule in normal subjects has long been recognized as a common MRI finding, perhaps reflecting a loss of myelinated fibers with normal aging or the different orientation of parietopontine tract ${ }^{19}$. We found that precentral gyrus atrophy and focal cortical atrophy were more specific than CST hyperintensity in most subcortical locations, but this was at the expense of a very low sensitivity that would preclude usefulness in both the ALS clinical and research trial setting. It should be noted that our control group was not perfectly matched for age, being on average five years younger than ALS subjects. This is not expected to influence the overall interpretation of results: younger control subjects may be expected to have a lower rate of false positive MRI interpretation, and our study did not find MRI to be a sensitive or specific indicator of ALS.

Hecht et $a l^{20}$ analyzed FLAIR hyperintensity along the CST in 31 patients with ALS, compared to 33 controls. They concluded that hyperintense signals were more common in ALS on FLAIR imaging at the level of the subcortical precentral gyrus, centrum semiovale, internal capsule and crus cerebri. This was however only true for the smaller subset of patients showing a "distinct" hyperintensity (isointense to the insular cortex), whereas a "mild" hyperintensity (isointense to the caput of the caudate nucleus) did not discriminate ALS and controls. In a study of 80 ALS patients, Abe et $a l^{21}$ found that $65 \%$ of patients and $51 \%$ of controls showed hyperintensity of the posterior limb of the internal capsule on both T2 and proton density sequences. Several recent reviews on the role of MRI as a biomarker for ALS have thus concluded that the finding of CST hyperintensity on T2, FLAIR or PD cannot be considered a reliable indicator because of its poor sensitivity and specificity $^{22-24}$.

This study also carefully assessed clinical features that might be postulated to influence the likelihood of detecting CST abnormalities on MRI. As might be expected, there was an association with disease stage (higher rate of abnormality in probable/definite ALS than in suspected/possible ALS). We did not find a correlation with the rate of progression, as estimated by the total disease duration. Thus conventional MRI in our patient population could not be relied upon to help predict survival prognosis.

Degeneration of direct and indirect descending motor pathways is expected to be manifested clinically with signs of spastic paresis, hyperreflexia, Babinski sign and pseudobulbar palsy. Our study however did not show a clear relationship between the MRI finding of CST hyperintensity and a predominance of such upper motor neuron signs, as opposed to the presence of clinical and EMG evidence of lower motor neuron involvement. This was true at the bulbar, cervicobrachial and lumbosacral levels. CST hyperintensity, albeit of low sensitivity and specificity, may thus be a marker of the presence and severity of the ALS disease process, but without a rigorous clinical-radiologic correlation for involvement of upper or lower motor neurons. The present study suggests that a normal conventional MRI has little negative or positive predictive value 
for a patient with suspected ALS, even in the presence of obvious upper motor neuron deficits.

Given the failure of many therapeutic trials in symptomatically advanced ALS, there remains a pressing need for reliable biomarkers in the very early stages of this condition. Conventional MRI sequences have not proved to be a reliable surrogate, and should mainly be used to exclude alternative diagnostic considerations. The future of neuroimaging in ALS may depend on finding a multimodal approach that relies on newer functional and structural strategies, including Radionuclide imaging (PET), Voxel and surface-based MRI morphometry, diffusion tensor imaging, functional MRI, and/or magnetic resonance spectroscopy ${ }^{25}$.

\section{ACKNOWLEDGEMENTS}

The authors thank Dr. Tim Ramsay (Scientific Director, Methods Center, Ottawa Hospital Research Institute) for his expertise with statistical analysis and Ms. Sue McNeely (ALS clinic, the Rehabilitation Centre) for her help with accessing clinical data.

\section{REFERENCES}

1. Filippi M, Agosta F, Abrahams S, Fazekas F, et al. EFNS guidelines on the use of neuroimaging in the management of motor neuron diseases. Eur J Neurol. 2010 Apr;17(4):526-e20.

2. Iwasaki Y, Kinoshita M, Ikeda K, Takamiya K, Shiojima T. MRI in patients with amyotrophic lateral sclerosis: correlation with clinical features. Int J Neurosci. 1991 Aug;59(4):253-8.

3. Mascalchi M, Salvi F, Valzania F, Marcacci G, Bartolozzi C, Tassinari CA. Corticospinal tract degeneration in motor neuron disease. Am J Neuroradiol. 1995 Apr;16(4 Suppl):878-80.

4. Friedman DP, Tartaglino LM. Amyotrophic lateral sclerosis: hyperintensity of the corticospinal tracts on MR images of the spinal cord. Am J Roentgenol. 1993 Mar;160(3):604-6.

5. Iwasaki Y, Ikeda K, Shiojima T, Tagaya M, Kurihara T, Kinoshita M. Clinical significance of hypointensity in the motor cortex on T2-weighted images. Neurology. 1994 Jun;44(6):1181.

6. Cheung G, Gawel MJ, Cooper PW, Farb RI, Ang LC. Amyotrophic lateral sclerosis: correlation of clinical and MR imaging findings. Radiology. 1995;194:263-70.

7. Hofmann E, Ochs G, Pelzl A, Warmuth-Metz M. The corticospinal tract in amyotrophic lateral sclerosis: a MRI study. Neuroradiology. 1998;40:71-75.

8. Oba H, Araki T, Ohtomo K, et al. Amyotrophic lateral sclerosis: T2 shortening in motor cortex at MR imaging. Radiology. 1993; 189:843-6

9. Waragai M. MRI and clinical features in amyotrophic lateral sclerosis. Neuroradiology. 1997 Dec;39(12):847-51.

10. Hecht MJ, Fellner F, Fellner C, Hilz MJ, Neundörfer B, Heuss D. Hyperintense and hypointense MRI signals of the precentral gyrus and corticospinal tract in ALS: a follow-up examination including FLAIR images. J Neurol Sci. 2002 Jul 15;199(1-2): $59-65$.
11. Zhang L, Ulug AM, Zimmerman RD, Lin MT, Rubin M, Beal MF. The diagnostic utility of FLAIR imaging in clinically verified amyotrophic lateral sclerosis. J Magn Reson Imaging. 2003 May;17(5):521-7.

12. Agosta $\mathrm{F}$, Chiò $\mathrm{A}$, Cosottini $\mathrm{M}$, et al. The present and the future of neuroimaging in amyotrophic lateral sclerosis. Am J Neuroradiol. 2010 Nov; 31(10):1769-77.

13. Imon Y, Yamaguchi S, Katayama S, et al. A decrease in cerebral cortex intensity on T2-weighted with ageing images of normal subjects. Neuroradiology. 1998 Feb;40(2):76-80.

14. Ngai S, Tang YM, Du L, Stuckey S. Hyperintensity of the precentral gyral subcortical white matter and hypointensity of the precentral gyrus on fluid-attenuated inversion recovery: variation with age and implications for the diagnosis of amyotrophic lateral sclerosis. Am J Neuroradiol. 2007 Feb;28 (2):250-4

15. Teriitehau C, Adamsbaum C, Merzoug V, Kalifa G, Tourbah A, Aubourg P. Subtle brain abnormalities in adrenomyeloneuropathy. J Radiol. 2007 Jul-Aug;88(7-8 Pt 1):957-61.

16. Loes DJ, Fatemi A, Melhem ER, et al. Analysis of MRI patterns aids prediction of progression in X-linked adrenoleukodystrophy. Neurology. 2003 Aug 12;61(3):369-74.

17. Kassubek J, Bretschneider V, Sperfeld AD. Corticospinal tract MRI hyperintensity in X-linked Charcot-Marie-Tooth Disease. J Clin Neurosci. 2005 Jun;12(5):588-9.

18. Bianco F, Fattapposta F, Locuratolo N, et al. Reversible diffusion MRI abnormalities and transient mutism after liver transplantation. Neurology. 2004 Mar 23;62(6):981-3.

19. Mirowitz S, Sartor K, Gado M, Torack R. Focal signal-intensity variations in the posterior internal capsule: normal MR findings and distinction from pathologic findings. Radiology. 1989 Aug; 172(2):535-9.

20. Hecht MJ, Fellner F, Fellner C, Hilz MJ, Heuss D, Neundörfer B. MRI-FLAIR images of the head show corticospinal tract alterations in ALS patients more frequently than T2-, T1- and proton-density-weighted images. J Neurol Sci. 2001 May 1;186 (1-2):37-44.

21. Abe K, Fujimura H, Kobayashi Y, Fujita N, Yanagihara T. Degeneration of the pyramidal tracts in patients with amyotrophic lateral sclerosis. A premortem and postmortem magnetic resonance imaging study. J Neuroimaging. 1997 Oct;7 (4):208-12.

22. Grosskreutz J, Peschel T, Unrath A, Dengler R, Ludolph AC, Kassubek J. Whole brain-based computerized neuroimaging in ALS and other motor neuron disorders. Amyotroph Lateral Scler. 2008 Aug;9(4):238-48.

23. Kassubek J, Ludolph AC, Müller HP. Neuroimaging of motor neuron diseases. Ther Adv Neurol Disord. 2012 Mar;5(2): 119-27.

24. Turner MR, Kiernan MC, Leigh PN, Talbot K. Biomarkers in amyotrophic lateral sclerosis. Lancet Neurol. 2009 Jan;8(1): 94-109.

25. Turner MR, Agosta F, Bede P, Govind V, Lulé D, Verstraete E. Neuroimaging in amyotrophic lateral sclerosis. Biomark Med. 2012 Jun;6(3):319-37. 